\title{
Distribution of polyprenol and dolichol in oil palm genotype (Elaeis guineensis) involving lipase activity
}

\author{
TENGKU SITI HABSYAH ${ }^{1}$, MOHAMMAD BASYUNI ${ }^{2, \bullet}$, LUTHFI A.M. SIREGAR ${ }^{3}$, DADANG AFANDI ${ }^{4}$, \\ INDRA SYAHPUTRA ${ }^{4}$ \\ ${ }^{1}$ Graduate School of Agrotechnology, Faculty of Agriculture, Universitas Sumatera Utara, Jl. Prof. A. Sofyan No. 3, Medan 20155, North Sumatra, \\ Indonesia \\ ${ }^{2}$ Department of Forestry, Faculty of Forestry, Universitas Sumatera Utara. Jl. Tridharma Ujung No. 1, Medan 20155, North Sumatra, Indonesia. \\ Tel./fax.: +62-61-8211920, `email: m.basyuni@usu.ac.id \\ ${ }^{3}$ Department of Agrotechonology, Faculty of Agriculture, Universitas Sumatera Utara. J1. Prof. A. Sofyan No. 3, Medan 20155, North Sumatra, Indonesia \\ ${ }^{4}$ PT. Socfin Indonesia. Jl. KL Yos Sudarso No. 106, Medan 20115, North Sumatra, Indonesia
}

Manuscript received: 14 December 2020. Revision accepted: 16 January 2021.

\begin{abstract}
Habsyah TS, Basyuni M, Siregar LAM, Afandi D, Syahputra I. 2021. Distribution of polyprenol and dolichol in oil palm genotype (Elaeis guineensis) involving lipase activity. Biodiversitas 22: 830-837. The aim of this study was to determine the pattern of chemical compounds from the polyisoprenoid group in oil palm plants that were contributing to the lipase activity. The study was conducted in two locations. A sampling of leaves and fruit mesocarp from 90 progenies was conducted at PT. Socfin Indonesia Aek Loba Plantation, Asahan District, North Sumatra, Indonesia. Biochemical analysis of polyisoprenoid was carried out at the Forest Biotechnology Laboratory, Faculty of Forestry, University of Sumatera Utara, Medan. The results showed that the total lipids in leaves tissue ranged from 0.40 to $1.032 \mathrm{mg} / \mathrm{g}$, with the lowest total lipid found in SL-4966 progeny and the highest total lipid found in SL-9737 progeny. Polyisoprenoid values ranged from 1.63 to $10.82 \mathrm{mg} / \mathrm{g}$ dry weight. The highest polyisoprenoid content was obtained in SL10682 progeny, and the lowest was in SL-5045 progeny leaf tissue. The polyisoprenoid in fruit mesocarp tissue ranged from 1.79 to 4.14 $\mathrm{mg} / \mathrm{g}$. The lowest polyisoprenoid content $(1.79 \mathrm{mg} / \mathrm{g})$ of fruit mesocarp was found in SL-4233 progeny, while the highest $(4.14 \mathrm{mg} / \mathrm{g})$ was found in SL-5010 progeny. Dolichol and polyprenol are equally dominant in palm leaves. Carbon polyprenol chain lengths ranged from $\mathrm{C} 45-\mathrm{C} 105$, and dolichol ranged from $\mathrm{C} 50-\mathrm{C} 110$. The polyprenol carbon chain lengths in the mesocarp tissues were C65-C120 and dolichol was C65-C125. Polyisoprenoid analysis on oil palm leaf and fruit mesocarp tissue showed that lipid patterns of oil palm leaf and mesocarp were categorized as type II lipid patterns. It provides important information for selecting genotypes of low lipase activity of oil palm plants.
\end{abstract}

Keywords: Dolichol, free fatty acid, low lipase activity, oil palm, polyprenol

\section{INTRODUCTION}

Oil palm is one of the most important and potential plantation commodities for the Indonesian economy in the short term and long term. Indonesia's palm oil production has been the largest in the world since 2008. Palm oil production reached 36.5 million metric tons or the equivalent of $53.5 \%$ of world palm oil production in 2017 (USDA 2017). Oil palm is the world's largest vegetable oil producer because its oil can be produced from both fruit and kernel fibers. The oil is used as cooking oil, industrial oil, and fuel (biodiesel). Other advantages of palm oil are high resistance to oxidation at high pressure, dissolve chemicals insoluble by other solvents, and a high coating capacity that can be used for various purposes (Ministry of Trade 2013).

One of the problems in palm oil production is the damage of the oil palm fruit. The oil palm may damage during harvesting, transporting, unloading at the loading ramp, and production process. The damage to oil palm fruit increases free fatty acid content due to acceleration of the hydrolysis process. Besides, long delays during the production process's waiting period lead to higher free fatty acid levels (Alfiah and Susanto 2015). Refined oil from fresh fruit bunches has excellent quality with a high carotene content, a deterioration of bleachability index (DOBI), and a low concentration of FFA, moisture, and impurities (Basyuni et al. 2017). The lengthy storage of the fruit significantly increased the FFA, moisture, and impurity contents of palm oil and significantly decreased carotene and DOBI (Basyuni et al. 2017).

The endogenous activity of the lipase enzyme has been reported to increase free fatty acids in oil palm plants (Tan et al. 2019). Lipases play important roles in lipid metabolism, lipid synthesis, and hydrolysis (Ding et al. 2019). Lipases hydrolyze ester groups such as triacylglycerols which cause the release of long-chain aliphatic acids from glycerol (Brockam 1984). This incomplete hydrolysis causes the release of monoacylglycerols and diacylglycerols, which increase free fatty acids (Pérez et al. 2017).

Free fatty acids levels continue to increase because free fatty acids naturally continue to form in the oil palm fruit that has been harvested along with the increasing delay period for processing (Pahan 2015). Dealing with this problem, it requires additional production costs which are expensive and less effective on a large scale. Another way to produce low levels of free fatty acids is by selecting 
plants or genotypes of oil palm plants with low lipase activity.

Generally, selection of plant diversity can be determined through morphological, biochemical, and molecular approaches. However, morphological markers have a weakness because these markers are influenced by the environment. Morphological markers have limitations because they are only able to distinguish visual diversity. Therefore, other markers are needed to provide more accurate results, namely biochemical markers through the chromatography method (Salah and Nofal 2020).

Polyisoprenoid biochemical markers can be used as chemotaxonomic markers (Afandi et al. 2019). Polyisoprenoid is a secondary metabolite of the terpenoid class, a related biochemical enhancer in the plant defense system against biotic and abiotic disorders (Zhang et al. 2008; Basyuni et al. 2019). Isoprenoids make up a wide variety of secondary metabolites including carotenoids, sterols, alcohol polyprenols, ubiquinone, and prenylated proteins. Triacylglycerols and carotenoids play an important role in regulating the function ripening of fruit and oil-rich fruit mesocarp (Tranbarger et al. 2011). Despite the importance of low lipase activity in oil palm, the study focused on the biochemical marker is still limited. The present study aimed to investigate the biochemical marker of polyisoprenoid for character selection involving lipase activity to develop oil plant breeding by thin-layer chromatography method.

\section{MATERIALS AND METHODS}

\section{Study area}

The research was conducted in 2 locations. Samplings of oil palm were conducted at PT. Socfin Indonesia Aek Loba Plantation, Asahan District, North Sumatra in December 2019. Biochemical analysis was carried out at the Forest Biotechnology Laboratory of the Faculty of Forestry, University of Sumatera Utara, Medan in February-November 2020. The materials used in this study were 90 genotypes of oil palms (Elaeis guineensis Jacq) consisting of 15 leaves and fruit mesocarp progenies and originated from the same plantation. Each progeny consists of 3 genotypes as a replication

\section{The procedure of polyisoprenoid isolation}

Polyisoprenoid isolation referred to the procedure by Sagami et al. (1992), Kurisaki et al. (1997), and Basyuni et al. 2019. Leaves and mesocarps of oil palms were dried at $60^{\circ} \mathrm{C}-75^{\circ} \mathrm{C}$ for $2-3$ days. The dried leaves and fruit mesocarps were crushed into a fine powder and immersed in chloroform/methanol (2: $1, \mathrm{vol} / \mathrm{vol})$ as a solvent for two days (Basyuni et al. 2019). Lipid extracts from leaves and fruit mesocarps were saponified at $65^{\circ} \mathrm{C}$ for 24 hours in $0.45 \mathrm{~g} \mathrm{KOH}, 2 \mathrm{ml}$ ethanol, and $2 \mathrm{ml}$ aqua dest. NSL (nonsaponifiable lipids) leaves and mesocarps were extracted with n-hexane and analyzed as previously described (Kurisaki et al. 1997; Sagami et al. 1992; Basyuni et al. 2018, 2019).

First-dimension TLC was carried out on a silica gel glass plate $(20 \times 3 \mathrm{~cm})$ with toluene: ethyl acetate $(9: 1)$ as a developing solvent for about $45 \mathrm{~min}$ as previously described (Basyuni et al. 2016). The longitudinal edge of the first-dimension TLC and the concentration zone of a reverse-phase C-18 TLC were clamped with magnetic bars. The silica gel glass and C-18 of TLC plate were then developed in acetone for about 30 minutes to transfer all compounds that have been separated in the first-dimension into concentration zone of the reverse-phase TLC plate. To determine the family of compounds of polyprenol or dolichol in samples, dolichols or polyprenols standards were added to the sample line and developed with a solvent system previously described. Spots of polyisoprenoid alcohol that had been developed using 2D-TLC were identified and visualized using iodine vapor. The chromatographic images were scanned using Canon G2000. The polyisoprenoid pattern of the samples was determined by comparing to dolichol or/and polyprenol standard on the TLC plate.

Polyisoprenoid content in samples was carried out by comparing with dolichol and polyprenol standard. A standard curve of dolichol or polyprenol concentration to iodine-color estimation was drawn. Dolichol and polyprenol in the samples were quantified using ImageJ ver. 1.46r (Schneider et al. 1992) and then compared to the standard curve that has been drawn previously.

\section{Cluster analysis}

Cluster analysis was performed on selected subsets of leaf and fruit mesocarp type data consisting of 15 variables, including polyprenols and dolichols from 15 leaf and fruit mesocarp type were log (10) transformed. From these data, dendrogram representing fruit type was drawn by cluster analysis using the unweighted-pair group method with arithmetic mean (UPGMA) and MVSP (multivariate statistical package) 3.22 (Kovach Computing Service). Euclidean distance was selected as the criterion for cluster combination.

\section{Free fatty acid (FFA) content}

The FFA content of 15 progenies one day after harvest was measured using the titration method described previously by Basyuni et al. (2017). Two g of oil preheated at $50{ }^{\circ} \mathrm{C}$ weighed in a beaker. Aliquots of ethanol $(50 \mathrm{uL})$ were added to the oil to dissolve the fatty acids. The ethanol-oil mixture was titrated with $0.1 \mathrm{~N} \mathrm{NaOH}$ using phenolphthalein as an indicator. $\mathrm{NaOH}$ required to produce a permanent pink color was recorded to determine the FFA content of the samples. (Basyuni et al., 2017).

\section{Data analysis}

Data from the analysis results are processed to identify the patterns and types of polyisoprenoids present in each sample. Lipid types and carbon chain patterns differentiate the type of FFA production in each sample. In each sample, the total lipid weight was calculated in relation to tissue weight $(\mathrm{mg} / \mathrm{g} \mathrm{dw})$. Meanwhile, the distribution of concentrations in each polyisoprenoid family was obtained using Image 1.5 I software (Scheinder et al. 2012) with dolichol and polyprenol standards as a comparison. 


\section{RESULTS AND DISCUSSION}

\section{Polyisoprenoids analysis by two-dimensional thin-layer chromatography}

Leaves and fruit mesocarp of low lipase activity oil palm were analyzed for their polyisoprenoid compounds and their amount. Distribution of polyprenol and dolichol in E. guineensis leaves was presented in Table 1. Total lipids in leaf tissue ranged from 0.40 to $1.032 \mathrm{mg} / \mathrm{g}$, and polyisoprenoid content ranged from 1.63 to $10.82 \mathrm{mg} / \mathrm{g}$ dry weight. The lowest total lipid was obtained in SL-4966 progeny, and the highest total lipid was in SL-9737 progeny. The highest polyisoprenoid content was obtained in SL-10682 progeny, and the lowest was in leaf tissue of SL-5045 progeny about $34-2.32 \mathrm{mg} / \mathrm{g}$. Polyisoprenoid content in fruit mesocarp tissue ranged from 1.79 to 4.14 $\mathrm{mg} / \mathrm{g}$. The lowest polyisoprenoid in mesocarp fruit was obtained from SL-4233 progeny (1.79 $\mathrm{mg} / \mathrm{g}$ ), and the highest was found in SL-5010 progeny (4.14 mg $/ \mathrm{g}$ ).

The distribution types of polyprenols and dolichols in plant tissue are classified into three types (Basyuni et al 2018). Type I has a higher dolichol content than polyprenol, which is more than $90 \%$. Type II has balanced polyprenol and dolichol. Type III has higher polyprenol compounds than dolichol which is more than $90 \%$. The results of isoprenoid analysis in oil palm leaf tissue (Table 1) showed that leaf tissue of oil palm has only type II lipid pattern. These findings supported the previous study by Arifiyanto et al. (2017) that type II lipid was present in oil palm Dura, Pisifera, and Tenera, oil palm infected with Ganoderma boninense (Afandy et al. 2019), oil palm in different land use (Basyuni et al. 2018).

\section{Quantification of polyisoprenoid compounds}

Table 2 and Figure 1 showed that dolichol and polyprenol in oil palm leaves shared the carbon chain length in polyprenol ranging from $\mathrm{C} 45-\mathrm{C} 105$, and dolichol C55-C110. The polyprenol carbon chain lengths in the mesocarp organ were $\mathrm{C} 65-\mathrm{C} 120$ and dolichol were C65C125. The most extended polyprenol carbon chain length was obtained in SL-5010 and SL-10682 progeny leaf tissue. The most extended dolichol carbon chain length was obtained in SL-7444 progeny. The shortest polyprenol carbon chain length was obtained in SL-7507 progeny and dolichol was in SL-6796 progeny.

The most extended polyprenol carbon chain length of mesocarp tissue was obtained in the progeny of SL-4966 and dolichol was obtained in the progeny of SL-5045 (C75C125). The shortest polyprenol carbon chain length was obtained in SL-7507 (C65 - C80) progeny, and the shortest dolichol carbon chain was SL-5133 and SL-7507 (C65C80) progeny. The results showed that leaf tissue and mesocarp had various carbon chain lengths. The length of the polyisoprenoid carbon chains in oil palms varies according to tissue type although in the same species and forms a particular dominant polyisoprenoid family (Arifiyanto et al. 2017).

Table 1. Distribution of polyprenol and dolichol compounds in the leaves and fruit mesocarp of oil palm

\begin{tabular}{|c|c|c|c|c|c|c|c|c|c|c|c|}
\hline \multirow{2}{*}{ Progeny } & \multirow{2}{*}{ Tissue } & \multirow{2}{*}{$\begin{array}{c}\text { TL } \\
(\mathrm{mg} / \mathrm{g} \mathrm{dw})\end{array}$} & \multirow{2}{*}{$\begin{array}{c}\text { PL } \\
(\mathrm{mg} / \mathrm{g} \mathrm{dw})\end{array}$} & \multirow{2}{*}{$\begin{array}{c}\text { Pol } \\
(\mathrm{mg} / \mathrm{g})\end{array}$} & \multirow{2}{*}{$\begin{array}{c}\text { Dol } \\
(\mathrm{mg} / \mathrm{g})\end{array}$} & \multicolumn{3}{|c|}{$\%$ in total lipid } & \multicolumn{2}{|c|}{$\%$ pada polyisoprenoid } & \multirow[b]{2}{*}{ Type } \\
\hline & & & & & & PL & Pol & Dol & Pol & Dol & \\
\hline SL-4233 & Leaves & $0.78 \pm 0.17$ & $3.89 \pm 0.90$ & $2.06 \pm 0.55$ & $1.83 \pm 0.35$ & 498.72 & 264.10 & 234.62 & 52.96 & 47.04 & II \\
\hline SL-4260 & Leaves & $0.56 \pm 0.32$ & $3.11 \pm 1.46$ & $1.36 \pm 0.62$ & $1.75 \pm 1.02$ & 555.36 & 242.86 & 312.50 & 43.82 & 56.18 & II \\
\hline SL-4966 & Leaves & $0.40 \pm 0.30$ & $6.27 \pm 6.54$ & $4.04 \pm 4.67$ & $2.23 \pm 1.87$ & 1569.37 & 1010.58 & 558.96 & 64.37 & 35.62 & II \\
\hline SL-5010 & Leaves & $0.98 \pm 0.40$ & $3.89 \pm 1.85$ & $2.0 \pm 1.9$ & $1.70 \pm 0.78$ & 397.09 & 260.61 & 195.83 & 56.41 & 43.59 & II \\
\hline SL-5045 & Leaves & $0.60 \pm 0.07$ & $1.63 \pm 0.31$ & $0.91 \pm 0.37$ & $0.83 \pm 0.49$ & 271.78 & 152.56 & 138.62 & 53.33 & 43.75 & II \\
\hline SL-5133 & Leaves & $0.62 \pm 0.22$ & $3.35 \pm 2.08$ & $1.41 \pm 1.11$ & $1.94 \pm 1.01$ & 535.62 & 225.24 & 310.38 & 42.05 & 57.95 & II \\
\hline SL-6796 & Leaves & $0.61 \pm 0.04$ & $4.28 \pm 2.32$ & $1.96 \pm 1.63$ & $2.32 \pm 0.81$ & 797.44 & 321.77 & 380.92 & 45.79 & 54.21 & II \\
\hline SL-7210 & Leaves & $0.66 \pm 0.11$ & $3.77 \pm 2.68$ & $2.28 \pm 2.12$ & $1.49 \pm 0.57$ & 572.20 & 345.71 & 226.49 & 60.42 & 39.58 & II \\
\hline SL-7444 & Leaves & $0.58 \pm 0.004$ & $2.55 \pm 0.92$ & $1.42 \pm 0.77$ & $1.12 \pm 0.23$ & 440.86 & 246.06 & 194.80 & 55.81 & 44.19 & II \\
\hline SL-7507 & Leaves & $0.62 \pm 0.02$ & $1.86 \pm 0.70$ & $0.79 \pm 0.38$ & $1.06 \pm 0.32$ & 300.70 & 128.61 & 172.09 & 42.77 & 57.23 & II \\
\hline SL-7993 & Leaves & $0.98 \pm 0.11$ & $3.23 \pm 1.19$ & $1.73 \pm 0.98$ & $1.50 \pm 0.21$ & 329.50 & 176.50 & 153.00 & 53.57 & 46.43 & II \\
\hline SL-9737 & Leaves & $1.03 \pm 0.68$ & $4.14 \pm 0.46$ & $2.08 \pm 0.33$ & $2.05 \pm 0.12$ & 401.94 & 271.61 & 49.13 & 50.30 & 49.67 & II \\
\hline SL-10682 & Leaves & $0.88 \pm 0.38$ & $10.82 \pm 3.51$ & $5.97 \pm 8.07$ & $4.84 \pm 5.44$ & 1237.26 & 683.09 & 554.17 & 55.21 & 44.79 & II \\
\hline SL-11181 & Leaves & $0.95 \pm 0.28$ & $5.56 \pm 1.26$ & $3.24 \pm 1.16$ & $2.23 \pm 0.77$ & 585.59 & 341.43 & 234.70 & 58.74 & 40.72 & II \\
\hline SL-11557 & Leaves & $0.91 \pm 0.32$ & $5.33 \pm 1.37$ & $2.38 \pm 1.01$ & $2.95 \pm 1.22$ & 586.80 & 261.83 & 324.86 & 44.62 & 55.36 & II \\
\hline SL-4233 & Mesocarp & $1.94 \pm 0.14$ & $1.79 \pm 0.76$ & $0.88 \pm 0.42$ & $0.91 \pm 0.35$ & 92.76 & 45.84 & 46.92 & 49.42 & 50.58 & II \\
\hline SL-4260 & Mesocarp & $1.77 \pm 0.06$ & $2.69 \pm 0.96$ & $1.22 \pm 0.48$ & $1.46 \pm 0.59$ & 152.32 & 69.33 & 83.03 & 45.25 & 54.49 & II \\
\hline SL-4966 & Mesocarp & $2.32 \pm 1.11$ & $3.19 \pm 0.84$ & $2.08 \pm 1.26$ & $1.11 \pm 0.56$ & 137.87 & 89.84 & 48.04 & 65.16 & 34.84 & II \\
\hline SL-5010 & Mesocarp & $1.97 \pm 0.14$ & $4.14 \pm 2.21$ & $2.08 \pm 1.13$ & $2.06 \pm 1.08$ & 210.48 & 105.83 & 104.65 & 50.28 & 49.72 & II \\
\hline SL-5045 & Mesocarp & $2.03 \pm 0.52$ & $3.55 \pm 0.37$ & $2.04 \pm 0.19$ & $1.51 \pm 0.54$ & 175.20 & 100.69 & 74.52 & 57.47 & 42.53 & II \\
\hline SL-5133 & Mesocarp & $1.70 \pm 0.15$ & $3.05 \pm 0.91$ & $1.66 \pm 0.21$ & $1.38 \pm 0.81$ & 179.69 & 97.86 & 81.72 & 54.52 & 45.48 & II \\
\hline SL-6796 & Mesocarp & $1.92 \pm 0.07$ & $3.85 \pm 2.37$ & $2.13 \pm 1.38$ & $1.72 \pm 1.06$ & 200.68 & 111.07 & 89.61 & 55.35 & 44.65 & II \\
\hline SL-7210 & Mesocarp & $1.80 \pm 0.14$ & $3.07 \pm 0.50$ & $1.59 \pm 0.17$ & $1.47 \pm 0.33$ & 170.64 & 88.58 & 82.06 & 51.91 & 48.09 & II \\
\hline SL-7444 & Mesocarp & $2.04 \pm 0.15$ & $3.07 \pm 0.89$ & $1.40 \pm 0.44$ & $1.66 \pm 0.50$ & 150.53 & 68.75 & 81.78 & 45.67 & 54.33 & II \\
\hline SL-7507 & Mesocarp & $2.04 \pm 0.24$ & $4.04 \pm 0.78$ & $1.92 \pm 0.23$ & $2.21 \pm 0.55$ & 198.53 & 94.25 & 104.27 & 47.48 & 52.52 & II \\
\hline SL-7993 & Mesocarp & $1.34 \pm 0.42$ & $3.28 \pm 1.30$ & $1.79 \pm 0.54$ & $1.49 \pm 0.75$ & 245.47 & 134.20 & 111.27 & 54.67 & 45.33 & II \\
\hline SL-9737 & Mesocarp & $1.91 \pm 0.18$ & $2.32 \pm 0.77$ & $0.95 \pm 0.37$ & $1.37 \pm 0.39$ & 121.62 & 49.88 & 71.73 & 41.01 & 58.99 & II \\
\hline SL-10682 & Mesocarp & $1.80 \pm 0.11$ & $2.57 \pm 0.58$ & $1.21 \pm 0.31$ & $1.35 \pm 0.36$ & 142.90 & 67.64 & 75.26 & 47.34 & 52.66 & II \\
\hline SL-11181 & Mesocarp & $1.79 \pm 0.12$ & $2.66 \pm 1.03$ & $1.32 \pm 0.41$ & $1.34 \pm 0.63$ & 149.13 & 74.08 & 75.05 & 49.67 & 50.33 & II \\
\hline SL-11557 & Mesocarp & $1.67 \pm 0.05$ & $3.06 \pm 0.87$ & $1.59 \pm 0.64$ & $1.47 \pm 0.24$ & 183.81 & 95.67 & 88.15 & 52.05 & 47.95 & II \\
\hline
\end{tabular}

Note: dw: dry weight. TL: Total Lipid. PL: Polyisoprenoid. Pol: Poliprenol. dan Dol: Dolychol 


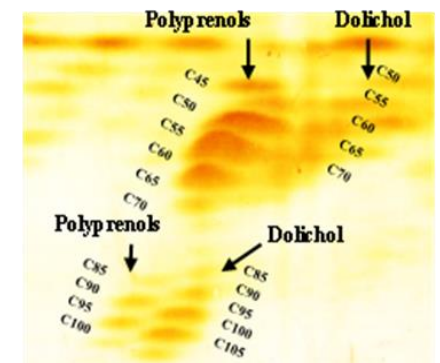

A

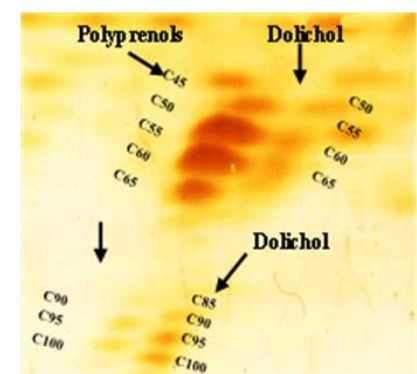

B
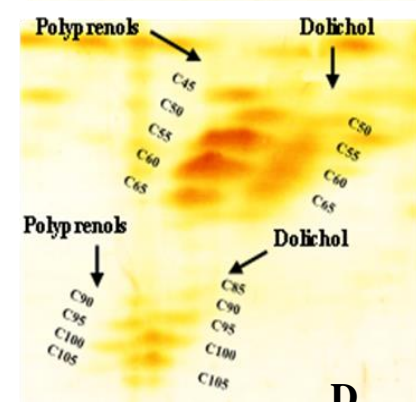

D
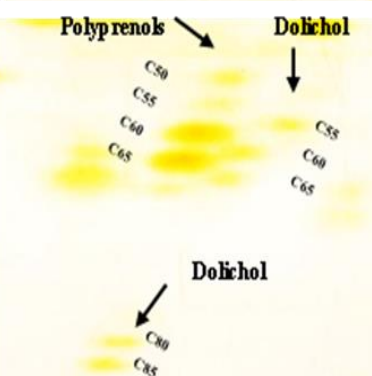

G

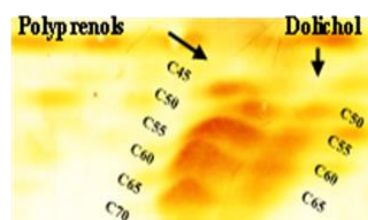

Polyprenol $\downarrow$
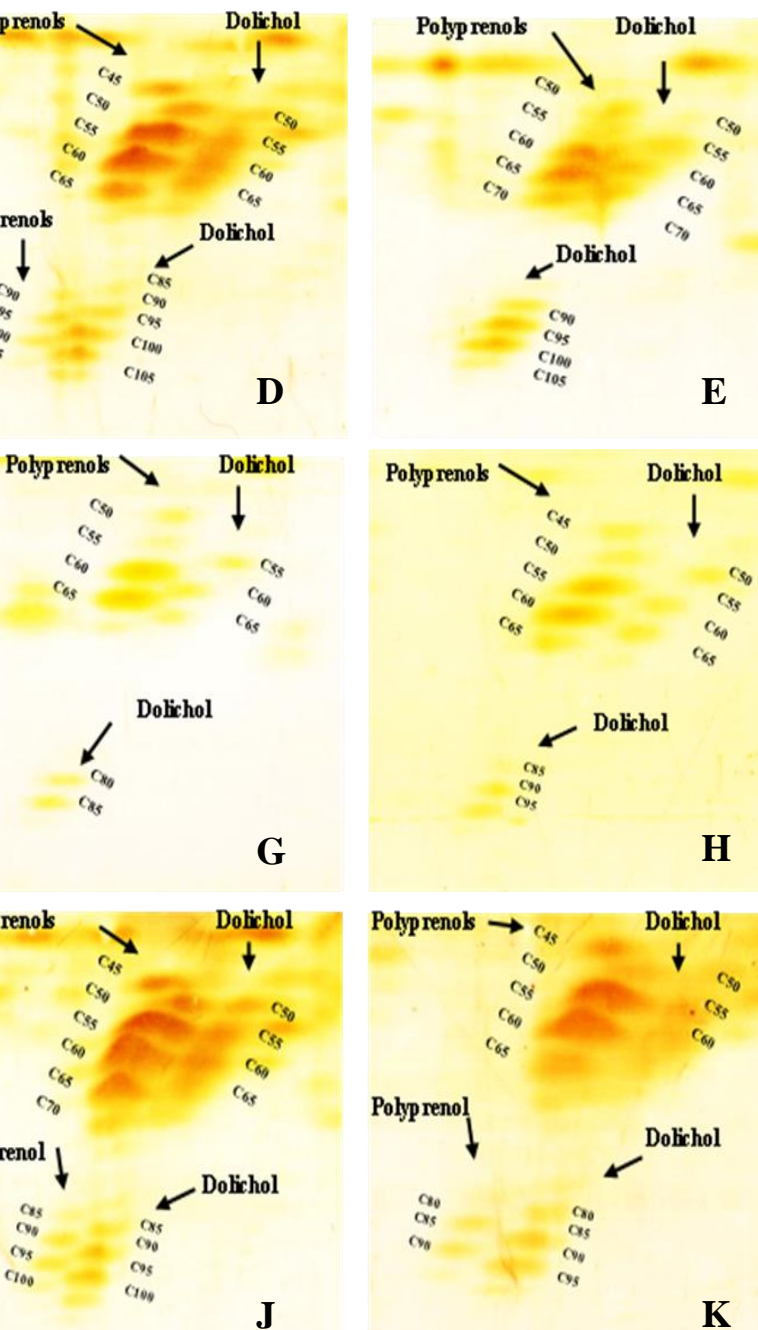

E

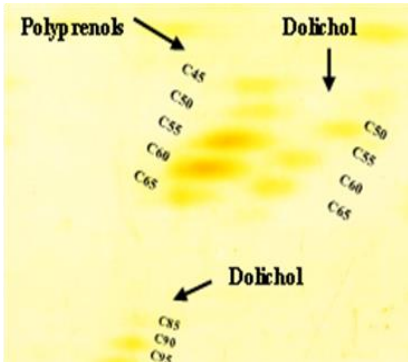

H
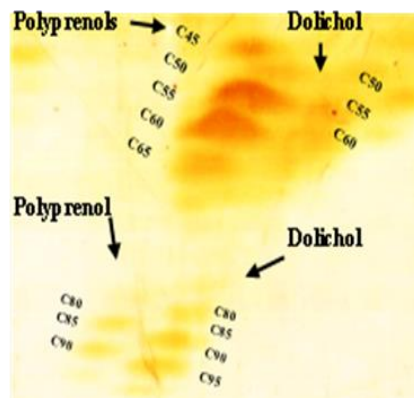

K

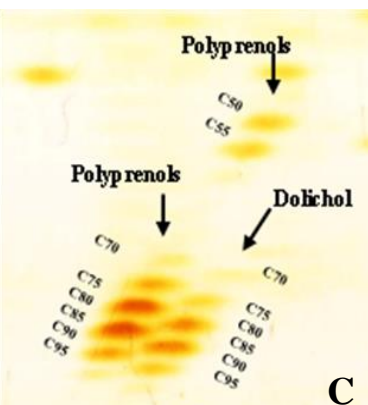

C

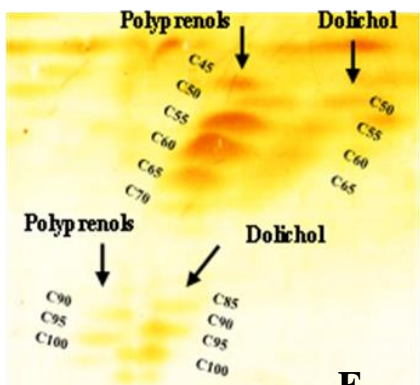

F

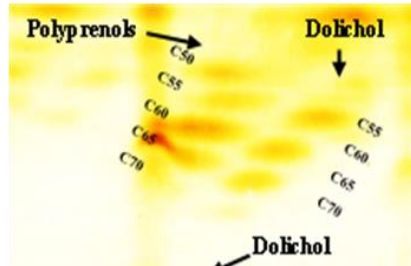

$\cos _{100}$ Cios $\mathrm{C}_{110}$

\section{I}

L

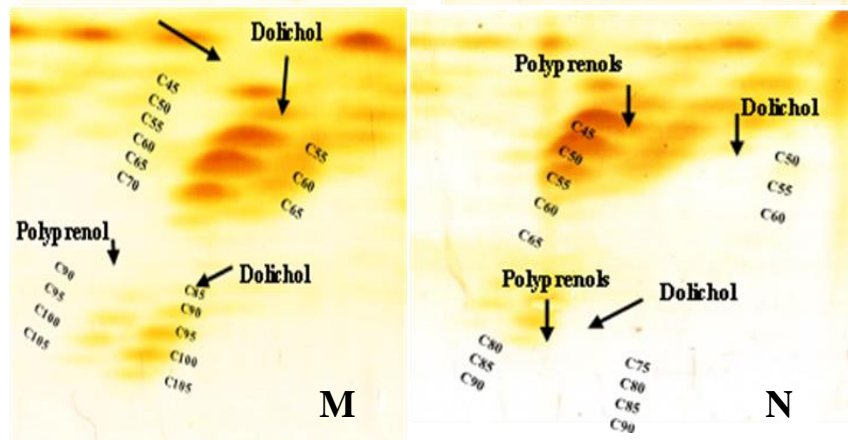

Figure 1.Two-dimensional thin layer chromatography (2D-TLC) of polyisoprenoid leaves tissue: A. SL-4233, B. SL-4260,C. SL-4996, D. SL-5010, E. SL-5045, F. SL- 5113, G. SL-6796, H. SL-7210, I. SL-7444, J. SL-7507, K. SL-7993, L. SL-9737, M. SL-10682, N. SL11181, O. SL-11557 


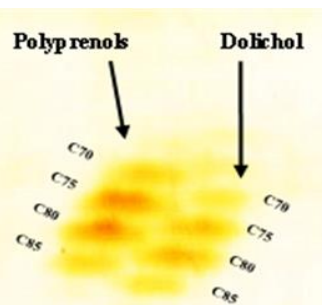

A

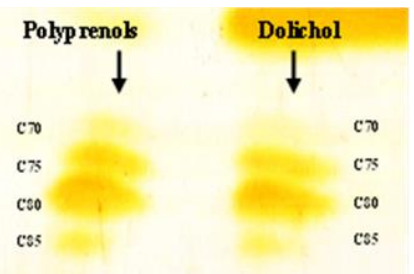

D
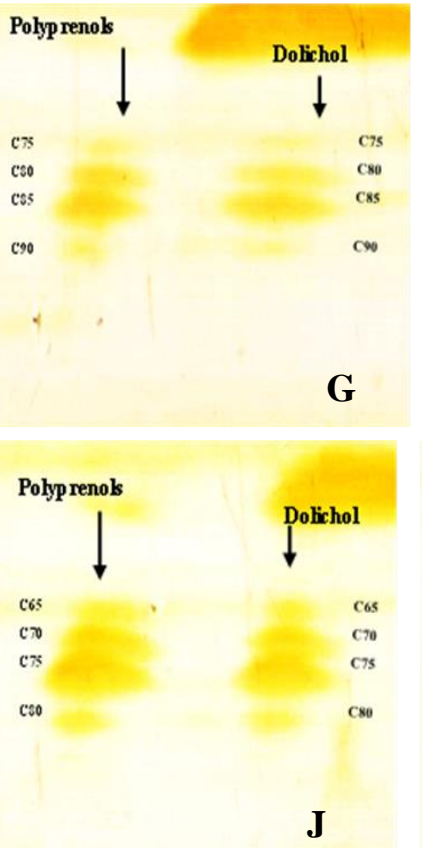

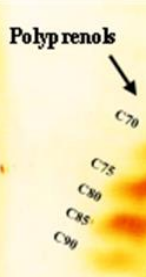

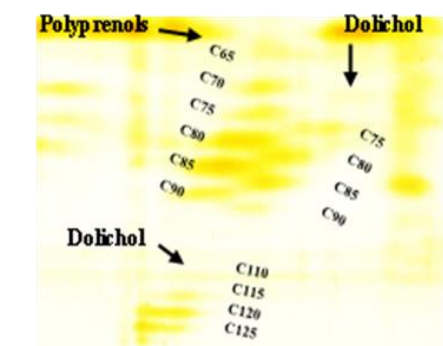

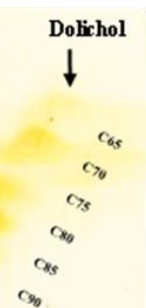

B

$\mathbf{E}$

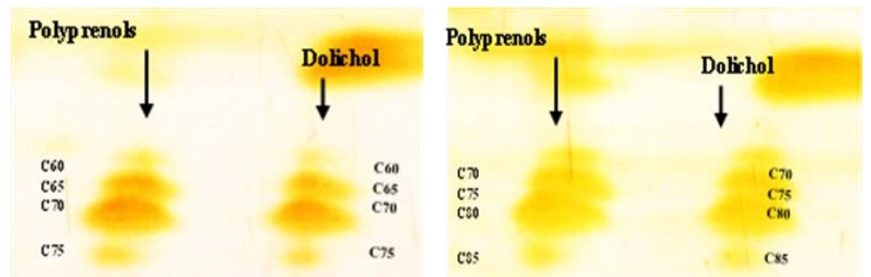

H

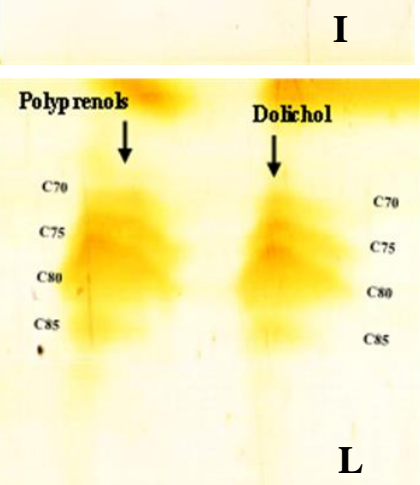

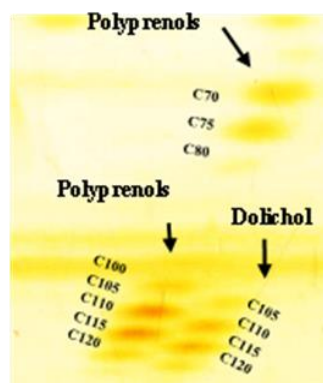

C

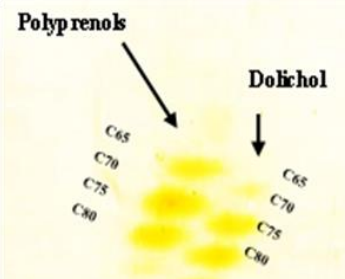

F
K

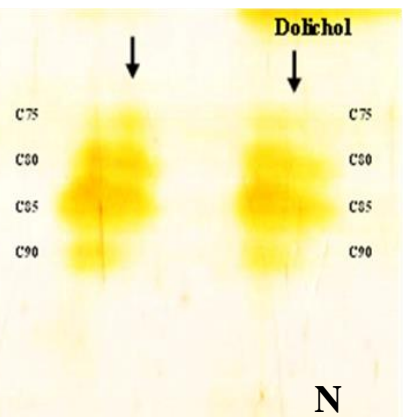

$\mathbf{L}$

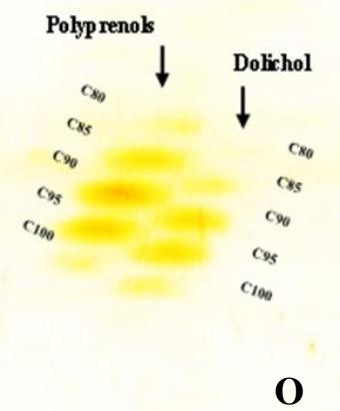

Figure 2. Two-dimensional thin-layer chromatography (2D-TLC) of polyisoprenoid fruit mesocarp tissue: A. SL-4233, B. SL-4260,C. SL-4996, D. SL-5010, E. SL-5045, F. SL- 5113, G. SL-6796, H. SL-7210, I. SL-7444, J. SL-7507, K. SL-7993, L. SL-9737, M. SL10682, N. SL-11181, O. SL-11557 
Table 2. Carbon-chain length in polyprenol and dolichol in leaves and fruit mesocarp

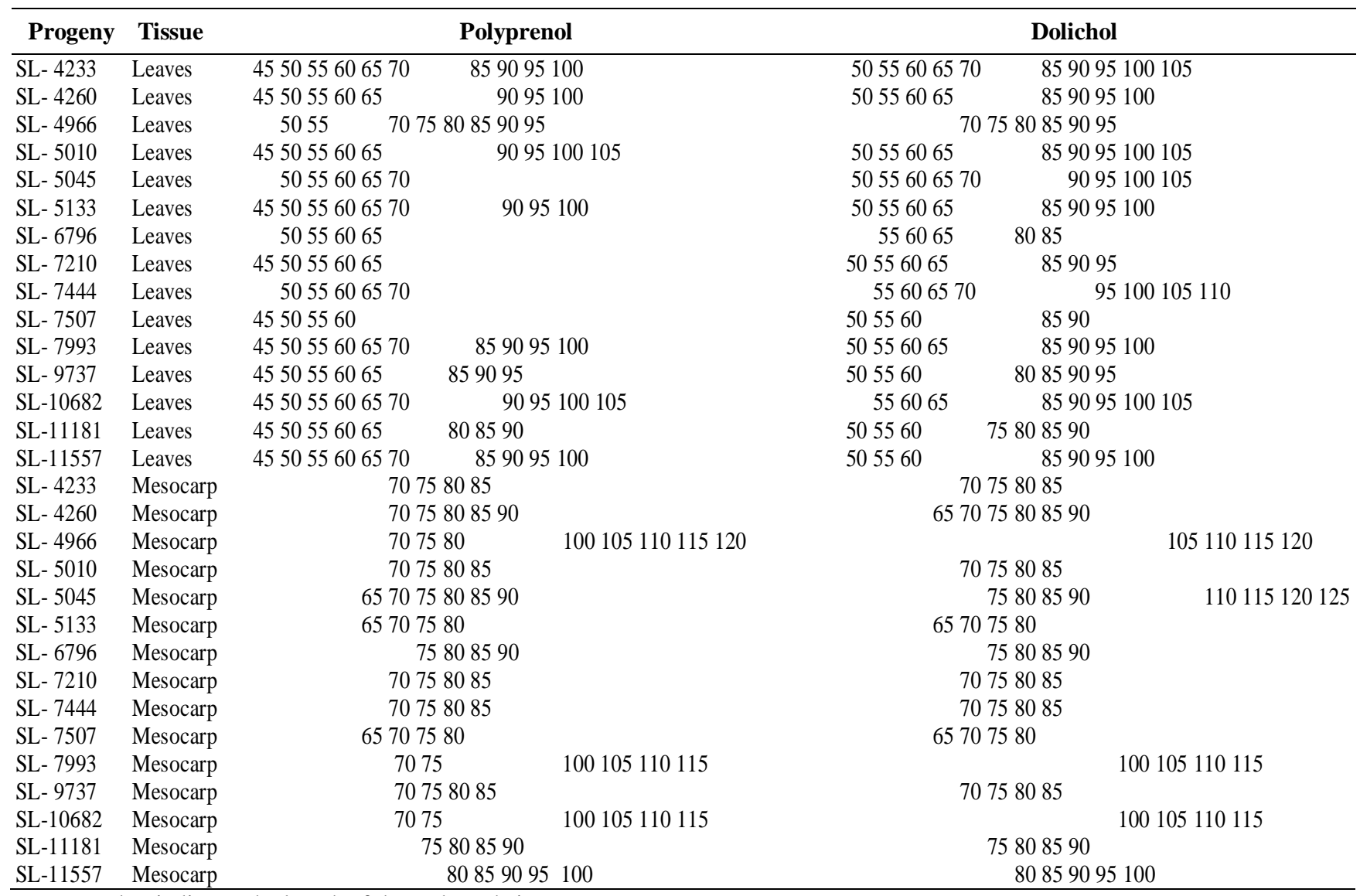

Note: number indicates the length of the carbon chain

The difference in the length of the polyisoprenoid carbon chain in oil palm leaves (E. guineensis) is caused by several factors, including the age of tissue (tissue aging), salinity stress, tissue differences (Basyuni et al. 2018). Dolichol acts as a sugar-carrying lipid in N-glycoprotein biosynthesis. The distribution of polyprenol long chains is not always the same as dolichol long chains in the same organ (Tateyama et al. 1999).

\section{Lipase activity grouping based on the carbon chain}

The result of TLC analysis, i.e., the carbon-chain composition from 15 progenies consisting of two plant tissues (leaves and mesocarps) was visualized by dendrogram using the UPGMA method. The dendrogram classifies plants into the cluster of desired traits based on the similarity of their carbon chain composition.

Figure 3 showed that 15 oil palm progeny were grouped into two main groups based on the carbon chain of leaves tissue. The first group consisted of SL-7507. SL-5133. SL6796. SL-11557 and SL-4260 had a higher percentage of dolichol content than polyprenol). The 2nd group comprised SL-11181. SL-7210. SL-4966. SL- 9737. SL5045. SL-10682. SL-7444. SL-5010. SL-7993 and SL4233) have a higher percentage of polyprenol content than dolichol. However, based on the euclidean distance of 0.009 , the oil palm leaves were grouped into three groups: the IA sub-group consisted of SL-7507. SL-5133. SL-6796. SL-11557 and SL-4260 had a higher dolichol content than polyprenol. The IB sub-group consisted of SL-11181. SL7210 and SL-4966 have the highest percentage of polyprenol content among other progeny. Group II included SL-9737. SL-10682. SL-7444. SL-5010. SL-7993 and SL-4233 had a higher percentage of polyprenol than dolichol.

Based on the grouping results of the carbon chain of the leaves tissue, so the 15 oil palm progeny are separated into two different groups due to the difference in the content of polyprenol and dolichol in the same tissue. It is consistent with the study of Tateyama et al. (1999) that the distribution of long-chain polyprenol was not always the same as long-chain dolichols in the same organ.

Figure 4 showed that at the Euclidean distance of 0.038 , 15 progeny of oil palm were grouped into two main groups based on polyisoprenoid content. The first group (SL-4966) has the highest percentage of polyprenol. The second group consisted of SL-9737, SL-6796, SL-7993, SL-5133, SL5045, SL-10682, SL-7507, SL-7444, SL-4260, SL-11557, SL-7210, SL-5010, SL-11181, and SL-4233) which have almost the same percentage of polyprenol and dolichol. However, at the Euclidean distance of $0.017,15$ progeny of oil palm were separated into three groups, i.e., subgroup IA consisting of SL-4966 which has the highest percentage of polyprenol. Subgroup IB consists of SL-9737 which has the highest percentage of dolichol. Group II consists of SL6796, SL-7993, SL-5133, SL-5045, SL-10682, SL-7507, SL-7444, SL-4260, SL-11557, SL-7210, SL-5010, SL- 
11181, and SL-4233 which have almost the same percentage of polyprenol and dolichol. The long-chain dolichol varies from tissue to tissue even within the same species and appears to form a predominance of distinct families. There are differences in the polyisoprenoid chain's length caused by several factors, including an increase in age (tissue aging) (Swiezewska et al. 2005; Kania et al. 2011). Oil palm plants that grow in different areas may differ in the length of the carbon chains of polyisoprenoid compounds (Basyuni et al. 2018).

Table 3, shows that the FFA content did not always correlate with the lipase activity prediction. We identify that leaf progenies with short polyprenol (ficaprenol) were predicted to have high lipase activity (Table 2, Figure 1, and Table 3) that are SL-5045, SL-6796, SL-7210, and SL7444, and one moderate lipase activity (SL- 7507). Both shorter and longer-chain polyprenol in oil palm leaf progenies generally has low to moderate lipase activity. In contrast, polyisoprenoid composition in mesocarp could not be used to differentiate lipase activity. SL-4966 was differentiated as oil palm progeny with low lipase activity (Figure 4); however, other progenies (SL-5045, SL-6796, SL-7210, and SL-7444) with low lipase prediction belong to progeny with high lipase activity. Mesocarp of oil palm fruit contains high lipase activity which can increase free fatty acids (Morcillo et al. 2013). This present study suggests that the phylogenetic tree relationships have limitations for predicting the level of lipase activity. However, this circumstance does not necessarily negate the presence of shorter to longer carbon chain length of polyprenols in oil palm because polyprenol reductase enzymes are widely distributed in plants (Tateyama et al. 1999; Swiezewska and Danikiewicz 2005; Zhang et al. 2008; Basyuni et al. 2018, 2019).

UPGMA

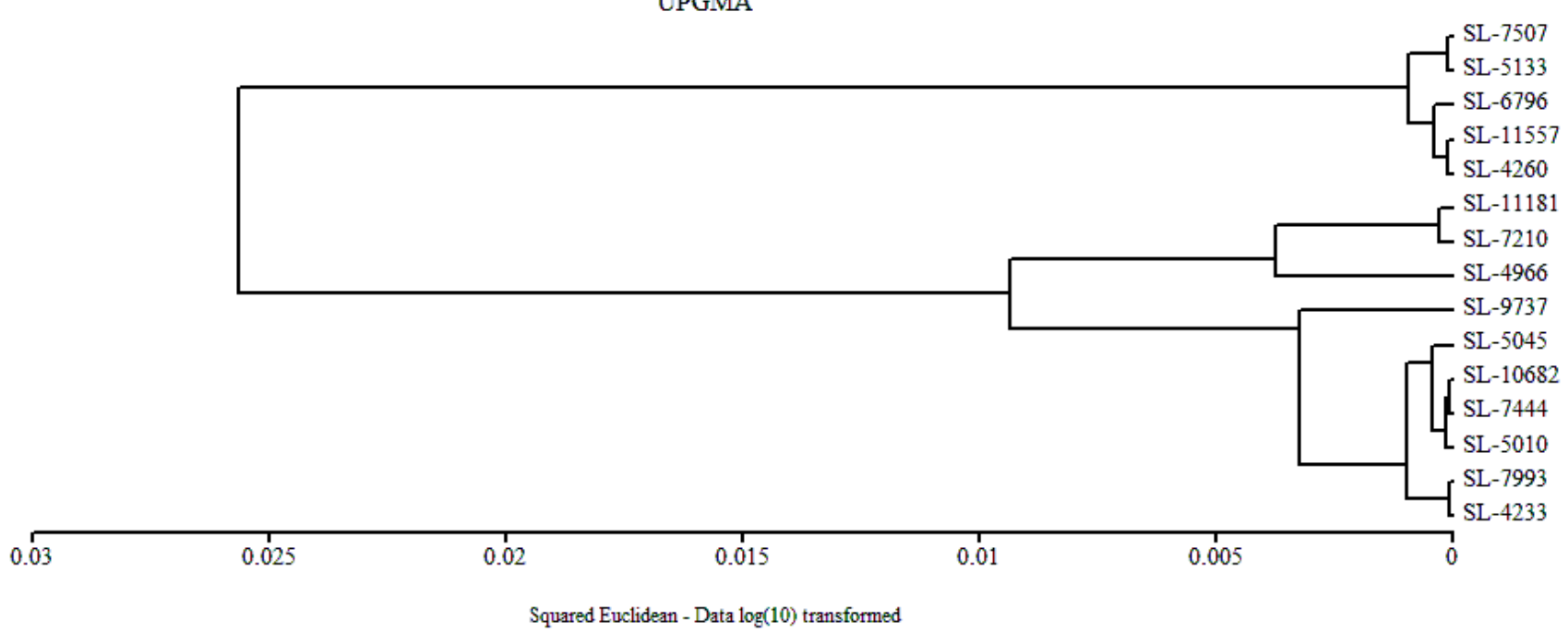

Figure 3. Dendrogram of 15 oil palm progeny based on the length of the polyisoprenoid carbon chain in leaves using log (10) transformation with Square Euclidean distance

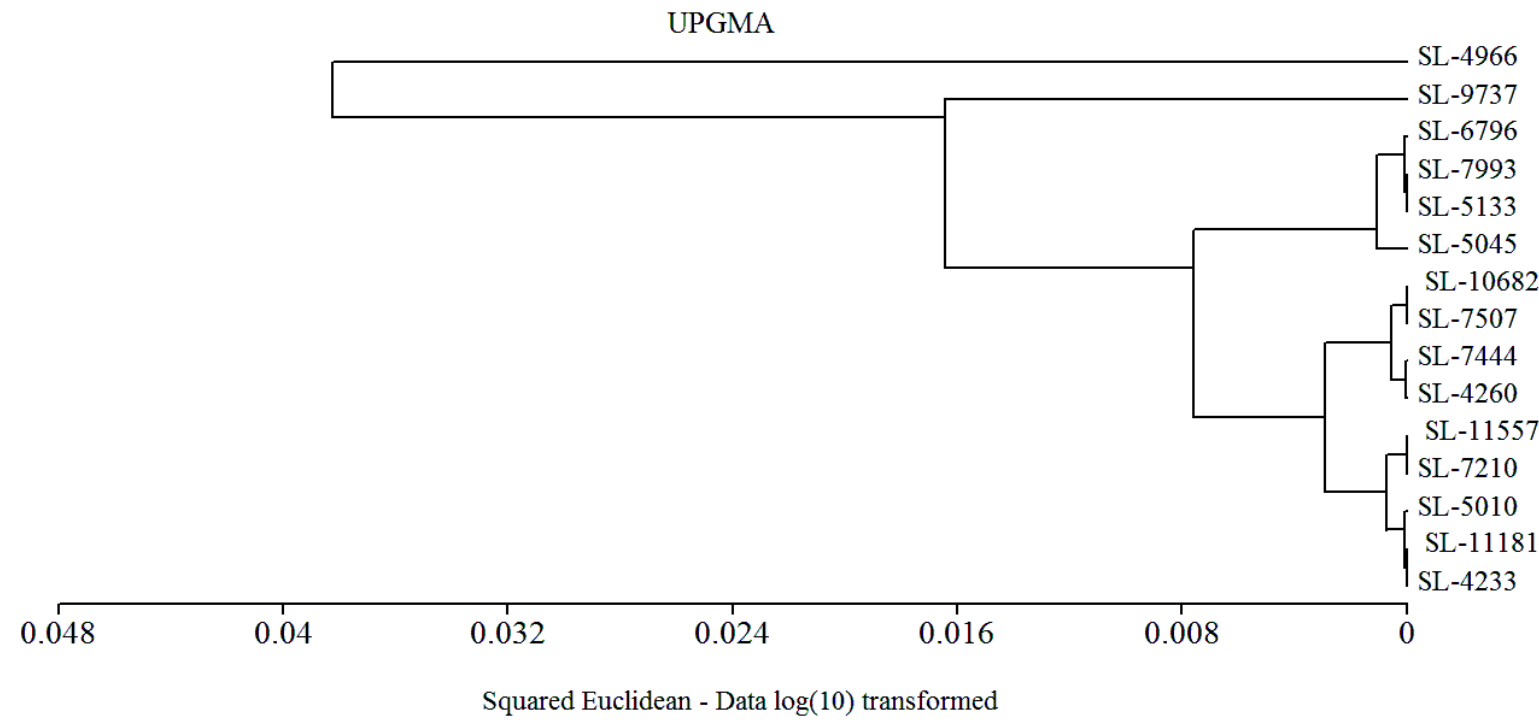

Figure 4. Dendrogram of 15 oil palm progeny based on the length of the polyisoprenoid carbon chain in fruit mesocarp using log (10) transformation with square Euclidean distance 
Table 3. FFA content at one day after harvest and the prediction of lipase level

\begin{tabular}{lcl}
\hline Progeny & FFA content $(\boldsymbol{\%})$ & Lipase prediction \\
\hline SL- 4233 & 0.88 & Low lipase \\
SL- 4260 & 1.19 & Low lipase \\
SL- 4966 & 2.24 & Low lipase \\
SL- 5010 & 2.09 & High lipase \\
SL-5045 & 0.50 & High lipase \\
SL-5133 & 0.32 & Moderate lipase \\
SL- 6796 & 0.69 & High lipase \\
SL-7210 & 0.88 & High lipase \\
SL-7444 & 0.54 & High lipase \\
SL-7507 & 0.79 & Moderate lipase \\
SL- 7993 & 3.35 & Moderate lipase \\
SL- 9737 & 0.87 & Moderate lipase \\
SL-10682 & 1.86 & High lipase \\
SL-11181 & 0.98 & Low lipase \\
SL-11557 & 1.87 & High lipase \\
\hline
\end{tabular}

In conclusion, lipase activity in oil palm has been characterized by polyisoprenoid content. The present research is important to assist in selecting genotypes of oil palm plants related to lipase activity. Polysiprenoid could be used as biochemical marker for selecting oil palm related to lipase activity level.

\section{ACKNOWLEDGEMENTS}

This study was supported by the Directorate General of Research and Community Service, the Ministry of Research and Technology/National Agency for Research and Innovation of the Republic of Indonesia through Penelitian Tesis Magister Program $2020 \quad$ (No. 214/SP2H/AMD/LT/DRPM/2020).

\section{REFERENCES}

Alfiah C, Susanto WH. 2015. Post-harvest handling of oil palm (spraying $\mathrm{CaCl} 2$ and potassium sorbate on the quality of crude palm oil). Jurnal Pangan Agroindustri 3: 61-72. [Indonesian].

Afandi D, Basyuni M, Putri LAP, Chalil D, Syahputra I. 2019. Expression of oil palm (Elaeis guineensis) polyisoprenoids in response to Ganoderma boninense infection. Biodiversitas 20 (1): 68-76. DOI: 10.13057/biodiv/d200109

Arifiyanto D, Basyuni M, Sumardi, Putri LAP, Siregar ES, Risnasari I, Syahputra I. 2017. Occurrence and cluster analysis of palm oil (Elaeis guineensis) fruit type using two-dimensional thin-layer chromatography. Biodiversitas 18 (4): 1487-1492. DOI: 10.13057/biodiv/d180426

Basyuni M, Baba S, Inafuku M, Iwasaki H, Kinjo K, Oku H. 2009. Expression of terpenoid synthase mRNA and terpenoid content in salt-stressed mangrove. J Plant Physiol 166: 1786-1800. DOI: 10.1016/j.jplph.2009.05.008
Basyuni M, Amri N, Putri LAP, Syahputra I, Arifiyanto D. 2017. Characteristics of fresh fruit bunch yield and the physicochemical qualities of palm oil during storage in North Sumatra Indonesia. Indonesia J Chem 17 (2): 182-190.

Basyuni M, Wati R, Deni I, Tia AR, Siregar ES, Syahputra I. 2018. Cluster analysis of polyisoprenoid in oil palm (Elaeis guineensis) leaves in different land-uses to find the possible cause of yield gap from planting materials. Biodiversitas 19 (4): 1492-1501. DOI: 10.13057/biodiv/d190440

Basyuni M, Wasilah M, Hasibuan PAZ, Sulistiyono N, Sumardi S, Bimantara Y, Hayati R, Oku H. 2019. Salinity and subsequent freshwater influences on the growth biomass and polyisoprenoids distribution of Rhizophora apiculata seedlings. Biodiversitas 20 (1): 388-395. DOI: $10.13057 /$ biodiv/d200146

Brockman HL. 1984. General features of lipolysis reaction schemes interfacial structure and experimental approaches, In Borgastrom B and Brockman HL (ed). Elsevier, Amsterdam.

Ding LN, Li M, Wang W J, Cao J, Wang Z, Zhu KM, Yang YH, Li YL, Tan XL. 2019. Advances in plant GDSL lipases: from sequences to functional mechanisms. Acta Physiol Plant 41: 151. DOI: 10.1007/s11738-019-2944-4

Kurisaki A, Sagami H, Ogura K. 1997. Distribution of polyprenols and dolichols in soybean plant. Phytochem 44 (1): 45-50. DOI: 10.1016/S0031-9422(96)00400-1

Kani M, Spolnik G, Jozwiak A, Ples M, Swiezewska E, Danikiewicz W. 2011. Identification of polyisoprenoid alcohols and their derivatives in natural samples by HPLC method coupled with atmospheric pressure photoionization mass spectrometry. Chem Phys Lipid 1645: 538-541.

Ministry of Trade. 2013. Palm Oil Market Brief and Processes. ITPC. Hamburg. [Indonesian]

Morcillo F, Cros D, Billotte N, Ngando-Ebongue GF, Domonhédo H, Pizot M, Cullar T, Espeout S, Dhouib R, Bourgis F, Claverol, S, Tranbarger TJ, Nouy B, Arondel V. 2013. Improving palm oil quality through identification and mapping of the lipase gene causing oil deterioration. Nature Comm 4 (1): 1-8.

Pahan I. 2015. Complete Guide to Palm Oil (Upstream to Downstream Agribusiness Management). Penebar Swadaya, Jakarta. [Indonesian].

Pérez B, Li J, Guo, Z. 2017. Chemistry and properties of lipids and phospholipids. In Food Lipids: Chemistry, Nutrition, and Biotechnology, CRC Press.

Sagami H, Kurisaki A, Ogura K, Chojnacki T. 1992. Separation of dolichol from dehydrodolichol by sample two-plate thin layer chromatography. J Lipid Res 33: 1857-1861

Salah WA, Nofal M. 2020. Review of some adulteration detection techniques of edible oils. J Sci Food Agric. DOI: 10.1002/jsfa.10750

Schneider CA, Rasband WS, Eliceiri KW. 2012. NIH Image to ImageJ: 25 years of image analysis. Nat Method 9 (7): 671-675. DOI: 10.1038/nmeth.2089

Swiezewska E, Danikiewicz W. 2005. Polyisoprenoids: Structure. biosynthesis. and function. Prog Lipid Res 44 (4): 235-258. DOI: 10.1016/j.plipres.2005.05.002

Tateyama S, Wititsuwannakul R, Wititsuwannakul D, Sagami H, Ogura K. 1999. Dolichols of rubber plant. ginkgo and pine. Phytochem 51 (1): 11-15. DOI: 10.1016/S0031-9422(98)00581-0

Tranbarger TJ, Dussert S, Joët T, Argout X, Summo M, Champion A, Cros D, Omore A, Nouy B, Morcillo F. 2011. Regulatory mechanisms underlying oil palm fruit, mesocarp maturation, ripening and functional specialization in lipid and carotenoid metabolism. Plant Physiol 156 (2): 564-584. DOI: 10.1104/pp.111.175141

Zhang H, Ohyama K, Boudet J, Chen Z, Yang J, Zhang M, Muranaka T, Maurel C, Zhu JK,. Gonga Z. 2008. Dolichol biosynthesis and its effects on the unfolded protein response and abiotic stress resistance in Arabidopsis. Plant Cell 20 (7): 1879-1898. DOI: 10.1105/tpc. 108.061150

USDA. 2017. United States Department of Agriculture. Available from www.fas.usda.gov (last consult: 2019/12/5). 